\title{
Modernités 27: Mauvais genre. La satire littéraire moderne, Textes réunis et présentés par Sophie Duval et Jean-Pierre Saïdah
}

\section{Francesca Forcolin}

\section{(2) OpenEdition \\ Journals}

\section{Edizione digitale}

URL: http://journals.openedition.org/studifrancesi/7775

DOI: $10.4000 /$ studifrancesi. 7775

ISSN: 2421-5856

\section{Editore}

Rosenberg \& Sellier

\section{Edizione cartacea}

Data di pubblicazione: 1 décembre 2009

Paginazione: 686-687

ISSN: 0039-2944

\section{Notizia bibliografica digitale}

Francesca Forcolin, «Modernités 27: Mauvais genre. La satire littéraire moderne, Textes réunis et présentés par Sophie Duval et Jean-Pierre Saïdah», Studi Francesi [Online], 159 (LIII | III) | 2009, online dal 30 novembre 2015, consultato il 09 janvier 2021. URL: http://journals.openedition.org/ studifrancesi/7775 ; DOI: https://doi.org/10.4000/studifrancesi.7775

Questo documento è stato generato automaticamente il 9 janvier 2021.

\section{cc) $(9)$}

Studi Francesi è distribuita con Licenza Creative Commons Attribuzione - Non commerciale - Non opere derivate 4.0 Internazionale. 


\title{
Modernités 27: Mauvais genre. La satire littéraire moderne, Textes réunis et présentés par Sophie Duval et Jean- Pierre Saïdah
}

\author{
Francesca Forcolin
}

\section{NOTIZIA}

AA. VV., Modernités 27: Mauvais genre. La satire littéraire moderne, Textes réunis et présentés par Sophie DUVAL et Jean-Pierre SAÏDAH, Presses Universitaires de Bordeaux, 2008, pp. 463.

1 Il volume, composto da numerosi articoli raccolti dal Groupe de Recherche dell'Université di Bordeaux 3, è il ventisettesimo del ciclo Modernités, riflessione sulle opere, espressioni ed estetiche del "modernismo".

2 Il primo obiettivo di quest'opera collettiva, nata dai lavori dell'omonimo convegno, è quello di esplorare l'evoluzione della satira - "spirito", "moda", piuttosto che "genere", in quanto priva di uno statuto riconosciuto - dal declino delle opere in versi fino al periodo contemporaneo, chiarendone in maniera esauriente le caratteristiche.

Per fare ciò, l'opera adotta un'organizzazione di tipo diacronico: le differenti sezioni, composte da un numero variabile di articoli, sempre preceduti da una nota introduttiva, ci presentano l'evoluzione della satira a partire dal secolo xvIII con Swift e Voltaire, proseguono fino al xx secolo e giungono al xxI con l'epilogo. Attraverso opere maggiori e minori, viene analizzata la satira nell'ambito della poesia, del teatro, dell'opera, esplorando altresì il rapporto dello scrittore con la propria creazione.

4 Come informazione complementare e indispensabile prima della lettura degli articoli, gli autori nell'Avant-propos (pp. 5-14) analizzano, in poche pagine ma in maniera 
esauriente, la scrittura satirica fin dalle sue origini: la cosiddetta satura versificata, con le proprie regole e maestri (in particolare Lucilio e Orazio), genere aggressivo, che indulge alla derisione, alla critica e al disprezzo spesso acuto, offensivo e osceno, giustificandosi con l'intento di una missione morale, contro vizi e follie in nome della ragione e della giustizia. Genere obsoleto, vettore dell'attacco diffamatorio e personale, la satira viene condannata e considerata inutile dagli Illuministi, ma continua a prosperare camuffandosi sotto svariate versioni estetiche, trovando rifugio nella prosa (da cui si differenzia per lo sviluppo non lineare delle vicende e per la costruzione dei personaggi), nel pamphlet e nel genere drammatico.

5 La satira si introduce allora in ogni genere letterario: mescola variazioni tonali (dal macabro al ludico, dall'osceno all'erudito), sovvertendo e ridicolizzando le forme canoniche. La frammentazione, l'incoerenza, la confusione e la libertà espressiva hanno portato la satira a non beneficiare di una grande rispettabilità né di uno statuto riconosciuto; entità parassitaria e ribelle, fugge da ogni tipo di concettualizzazione critica. Proprio per questa sua caratteristica di essere un pot-pourri di forme ed espressioni, ancora oggi gran parte degli studi su questo anti e mauvais genre non godono di grande considerazione.

Da qui nasce il secondo obiettivo, di ordine pragmatico, del volume: il tentativo di sensibilizzare alla riflessione e allo studio della satira letteraria moderna, rimettendo in discussione un genere troppo spesso sottovalutato.

7 A introduzione delle sezioni, oltre all'Avant-propos, viene proposta anche l'Apologie Prologue théorique et métacritique: points de vue contemporains sur la satire (p. 15), che anticipa due articoli, due punti di vista differenti sulla satira: il primo, Satire et critique moderne: modèles, emprunts et perspectives dell'americano Fredric V. BOGEL, traccia la storia della critica moderna della satira; il secondo, La pensée de la satire del filosofo francese Pascal ENGEL, è una riflessione sulla concezione classica e moralizzatrice della satira. I due articoli sono essenziali per comprendere a fondo le letture delle sezioni successive.

8 La prima, dal titolo «À l'aube de la satire moderne: paradoxes et divergences du mode satirique au XVIII ${ }^{e}$ siècle» (pp. 47-76), raccoglie gli articoli di Marc MARTINEZ, Le Conte du tonneau de Jonathan Swift ou l'anatomie de la satire moderne, e di Michèle воковZA КАНАN, D’une satire qui s'ignore dans le Traité sur la tolérance.

9 Nell'ambito di «Poétiques de la réflexivité satirique au XIX ${ }^{e}$ siècle: satire de l'écrivain, auto-satire et poésie» (pp. 77-146) sono raccolti gli scritti di José-Luis DIAZ, La satire du poète à l'âge du "sacre de l'écrivain»; Matthieu LIOUVILLE, Romantisme et auto-satire; Stéphanie TRIBOUILLARD, Musset satiriste, des Lettres de Dupuis et Cotonet à «Dupont et Durand»; Sandrine BAZILE, «Un Hamlet de moins!» ou la déroute satirique du poète décadent Des suites «irrégulières» de la piété filiale... - Jules Laforgue, Moralités légendaires; Romain PIANA, Théodore de Banville et la satire aristophanesque au XIXe siècle.

10 L'obiettivo della terza sezione, «Problématiques satiriques de la nouvelle et du roman au XIX ${ }^{e}$ siècle: perspectives éthiques» (pp.147-220), è quello di riflettere sul rapporto tra satira e romanzo: può il romanzo adottare le caratteristiche del genere satirico mantenendo inalterate le proprie specificità? Gli articoli di Daniel GROJNOwSKI, «Satire de quoi»: Villiers et le conte cruel; Noëlle BENHAMOU, De qui se moque-t-on? La satire dans les «contes du prétoire» de Maupassant; Gérard PEYLET, Césarine Dietrich, roman satirique de George Sand?; Alexandre GEFEN, Du défaut de méthode dans les sciences: la satire des savoirs 
dans Bouvard et Pécuchet; e Marie-Françoise MELmouX-MONTAUBIN, L'œuvre de Georges Darien ou la satire au péril de la fiction riflettono su questa problematica.

11 La quarta sezione, «Un mode protéen: polymorphisme et hybridation» (pp. 221-312), comprende i contributi di Delphine GLEIZES, Du texte au dessein: l'écriture satirique hugolienne et ses implications graphiques; Françoise sYLvos, Satire et utopie (1800-1850); Sandrine BERTHELOT, Robert Macaire ou le brouillage satirique; Pierre LAFORGUE, Mours et satire chez Balzac (1829-1831); Jean-Marie SEILLAN, Satire et critique littéraire: Champfleury lecteur de Barbey, Bloy lecteur de Zola; Elisheva ROSEN, Dans le voisinage de la presse: satire et roman chez Balzac et chez Proust.

12 La quinta parte, dal titolo "Satire et catégories comiques: ironie, humour et parodie» (pp. 313-380), è composta dagli articoli di Isabelle DE VENDEUVRE, Satire et regard clinique dans les ceuvres de Proust et de James; Jonathan POLLocK, «Blast humour»: la surenchère satirique du mouvement vorticiste londonien; Daniel SANGSUE, Parodie et satire. L'exemple de Macbett d'Eugène Ionesco; Elisabeth GRODEK, Les avatars d'un topos satirique: la danse macabre et le triomphe de la mort au théâtre et à l'opéra (Ghelderode et Ligeti).

13 L'ultima sezione, "Un mode en quête de son dépassement: retournement et transfiguration dans la satire narrative $\mathrm{du} \mathrm{xx}^{\mathrm{e}}$ siècle» (pp. 381-444), riunisce le riflessioni di André TOPIA, Pourquoi Joyce n'est pas un satiriste; Fabienne RIHARD-DIAMOND, Le rigodon de Voyage: la satire célinienne entre danse et silence; Nicolas DI MÉO, Fascination et contestation: les ambiguités du discours satirique chez Paul Morand pendant l'entre-deux guerres; Thierry OZWALD, Écriture romanesque et retournement satirique chez Albert Cohen.

14 Chiude il volume l'«Epilogue réflexif: point de vue d'un satiriste contemporain» (pp. 445-463) che introduce l'articolo di Philippe CHARDIN Alma Mater, théorie et pratique. Professore di letteratura comparata e autore del volume edito nel 2000 Alma Mater, Chardin analizza, non solo in testi francesi, le difficoltà che sorgono per ogni autore di opere satiriche: domande e problemi nel corso della scrittura, fino all'edizione del testo.

15 Le ultime pagine del volume sono dedicate a una breve presentazione delle raccolte del ciclo Modernités dalla 1 alla 26. 